Ecography 33: 285-294, 2010

doi: $10.1111 /$ j.1600-0587.2010.06203.x

(C) 2010 The Authors. Journal compilation (C) 2010 Ecography

Subject Editor: Helmut Hillebrand. Accepted 12 March 2010

\title{
Extinction debt on oceanic islands
}

\author{
Kostas A. Triantis, Paulo A. V. Borges, Richard J. Ladle, Joaquín Hortal, Pedro Cardoso, \\ Clara Gaspar, Francisco Dinis, Enésima Mendonça, Lúcia M. A. Silveira, Rosalina Gabriel, \\ Catarina Melo, Ana M. C. Santos, Isabel R. Amorim, Sérvio P. Ribeiro, Artur R. M. Serrano, \\ José A. Quartau and Robert J. Whittaker
}

\begin{abstract}
K. A. Triantis (konstantinos.triantis@ouce.ox.ac.uk), Biodiversity Research Group, Oxford Univ. Centre for the Environment, South Parks Road, Oxford, OX1 3QY, UK, and Dept de Ciências Agrárias, Univ. dos Açores, CITAA (Azorean Biodiversity Group), Terra-Chãa, PT-9700851, Angra do Heroismo, Terceira, Açores, Portugal. - P. A. V. Borges, P. Cardoso, C. Gaspar, F. Dinis, E. Mendonça, L. M. A. Silveira, R. Gabriel, C. Melo and I. R. Amorim, Univ. dos Açores, Dept de Ciências Agrárias, CITAA (Azorean Biodiversity Group), Terra-Chã, PT9700-851, Angra do Heroismo, Terceira, Açores, Portugal. - R. J. Ladle, Biodiversity Research Group, Oxford Univ., Centre for the Environment, South Parks Road, Oxford, OX1 3QY, UK. - J. Hortal, NERC Centre for Population Biology, Imperial College at Silwood Park, Ascot, SL5 7PY, UK. - A. M. C. Santos, Div. of Biology, Imperial College at Silwood Park, Ascot, SL5 7PY, UK and Dept de Ciências Agrárias, Univ. dos Açores, CITAA (Azorean Biodiversity Group), Terra-Chã, PT-9700-851, Angra do Heroísmo, Terceira, Açores, Portugal. - S. Ribeiro, Univ. Federal de Ouro Preto, DEBIO/Inst. de Ciências Exatas e Biologicas, Lab. Evolutionary Ecology of Canopy Insects, 35400-000, Ouro Preto, MG, Brazil. - A. R. M. Serrano and J. A. Quartau, Centro de Biologia AmbientallDept de Biologia Animal, Faculdade de Ciencias da Univ. de Lisboa, R. Ernesto de Vasconcelos, C2, PT-1749-016 Lisboa, Portugal. - R. J. Whittaker, Biodiversity Research Group, Oxford Univ. Centre for the Environment, South Parks Road, Oxford, OX1 3QY, UK, and Centre for Macroecology, Evolution and Climate, Dept of Biology, Univ. of Copenhagen, DK-2100 Copenhagen, Denmark.
\end{abstract}

\begin{abstract}
Habitat destruction is the leading cause of species extinctions. However, there is typically a time-lag between the reduction in habitat area and the eventual disappearance of the remnant populations. These "surviving but ultimately doomed" species represent an extinction debt. Calculating the magnitude of such future extinction events has been hampered by potentially inaccurate assumptions about the slope of species-area relationships, which are habitat- and taxon-specific. We overcome this challenge by applying a method that uses the historical sequence of deforestation in the Azorean Islands, to calculate realistic and ecologically-adjusted species-area relationships. The results reveal dramatic and hitherto unrecognized levels of extinction debt, as a result of the extensive destruction of the native forest: $>95 \%$, in $<600$ yr. Our estimations suggest that more than half of the extant forest arthropod species, which have evolved in and are dependent on the native forest, might eventually be driven to extinction. Data on species abundances from Graciosa Island, where only a very small patch of secondary native vegetation still exists, as well as the number of species that have not been found in the last $45 \mathrm{yr}$, despite the extensive sampling effort, offer support to the predictions made. We argue that immediate action to restore and expand native forest habitat is required to avert the loss of numerous endemic species in the near future.
\end{abstract}

In their natural state, oceanic islands typically support a substantial proportion of endemic species, many of which have been lost as a direct consequence of recent human habitation (Steadman 2006, Whittaker and Fernández-Palacios 2007). The biodiversity "crisis" is thus nowhere more apparent and in need of urgent action than on remote islands (Paulay 1994). The majority of the documented extinctions since ca AD 1600 are of species endemic to oceanic islands. Although the specific causes of these extinctions are often difficult to attribute (Whittaker and Fernández-Palacios 2007), the primary drivers are the habitat destruction and fragmentation universally associated with human colonization, in combination with other factors such as the introduction of non-native species (Paulay 1994 May et al. 1995, Blackburn et al. 2004, Steadman 2006, Hanski et al. 2007, Whittaker and Fernández-Palacios 2007).

Habitat destruction is rarely absolute and typically results in many species being reduced to a few small, isolated populations, each susceptible to a variety of stochastic factors such as random fluctuations in demography, changes of the local environment and the erosion of genetic variability (Lande 1993). Hence, it can take several generations for the full impact of habitat destruction and fragmentation to be visible in the number of extinctions (Tilman et al. 1994, Helm et al. 2006, Vellend et al. 2006). 
This time-lag represents an "extinction debt" (Tilman et al. 1994) - a future ecological cost of habitat destruction that may not be initially apparent in studies made shortly after habitat loss has occurred. For this reason it is probable that the true ecological costs of the historically recent spate of habitat destruction, disturbance and fragmentation on many oceanic islands are yet to be realised (Diamond 1989), i.e. there exist many extant but seriously imperilled species.

Developing methods to quantify the magnitude and taxonomic distribution of the extinction debt is clearly important for effective conservation planning and prioritization. However, accurate assessment of extinction rates and their extrapolation into the future requires robust longterm data on species occurrences - data which are rarely available, especially for less conspicuous taxa such as invertebrates. The lack of appropriate knowledge has led to an inevitable reliance on indirect measures and theoretical projections of extinctions (McDonald and Brown 1992, Heywood et al. 1994, May et al. 1995, Pimm et al. 1995, Brooks et al. 1997, Rosenzweig 2001, Brook et al. 2003, Whittaker et al. 2005, Kuussaari et al. 2009, Ladle 2009).

One of the most commonly used methods for estimating future extinctions is to extrapolate from the characteristic form of the classic island species-area relationship $\left[S=\mathrm{cA}^{\mathrm{z}}\right.$, where $S$ is the number of species, $A$ is (island) area, and $c$ and $\mathrm{z}$ are constants] derived from island biogeography theory (Preston 1962, MacArthur and Wilson 1967). The consequences of habitat loss under this framework can be predicted following the "rule of thumb" calculation that a 10 -fold decrease in area results in a twofold decrease in species (Darlington 1957), or alternatively, when an area of habitat is reduced by $90 \%$, the number of species eventually drops to one half. This approach has been applied at varying - sometimes very coarse - scales to forecast species losses as a function of habitat loss due to factors such as deforestation (Brooks et al. 2002) or future climate change (Thomas et al. 2004). Even though the accuracy of this approach critically rests upon accurate estimation of the slope (z) of the relationship (Rosenzweig 2001, Whittaker et al. 2005, Lewis 2006, Whittaker and Fernández-Palacios 2007), it has been commonplace to assume $z=0.25$ across a range of different taxonomic groups, scales and ecogeographical systems (May et al. 1995, Brooks et al. 2002, Thomas et al. 2004).

Although arthropods represent the bulk of all known living species, the level of threat imposed by global environmental changes to arthropod diversity remains poorly documented (Brooks et al. 2006, Fonseca 2010). Dunn (2005) has estimated that roughly 44000 insect extinctions have occurred in the last $600 \mathrm{yr}$, but the number of extinctions documented during this period is 61 species (IUCN 2009; the respective number for arachnids is zero). Here, we apply a method that uses the historical information on deforestation on the Azores (a remote Atlantic Ocean archipelago) to generate more accurate estimates of local extinctions or extirpations (hereafter extinctions) for the endemic forest-dependent species of three well-studied groups of arthropods from the Azores, namely the spiders (Araneae), the true bugs (Hemiptera) and the beetles (Coleoptera). This approach has been used in a few mainland systems (Pimm and Askins 1995, Helm et al.
2006, see also Kuussaari et al. 2009 for a recent review) but we are not aware of any similar study on islands, despite the widely accepted notion that islands and especially oceanic islands have suffered and will probably suffer increased extinctions following habitat loss.

The Azores constitute an ideal model system for assessing extinction debt because: 1) they have lost $>95 \%$ of their original native forest during the six centuries of human occupation; 2) being one of the most isolated archipelagos on Earth they support a significant number of single island endemic species (SIE; i.e. endemic species restricted to one island) (Borges et al. 2005b, Borges and Hortal 2009, Cardoso et al. 2010); 3) the history of human settlement and deforestation is well known (Frutuoso 1963, Silveira 2007), and; 4) extensive distributional data exist for a range of taxa (Borges et al. 2005b).

\section{Methods}

\section{Study area}

The first human settlements were established in the Azores (Supplementary material Fig. S1) around AD 1440. More than $550 \mathrm{yr}$ of human presence has taken its toll on the local fauna and flora, 420 species of which (out of the 4467 total terrestrial taxa known from the Azores) are endemic to the archipelago (Borges et al. 2005b). Today, ca $70 \%$ of the vascular plant species and $58 \%$ of the arthropod species found in the Azores are exotic, many of them invasive (Borges et al. 2005b, 2006). The native "laurisilva", a humid evergreen broadleaf laurel forest, was the predominant vegetation form in the Azores before human colonization in the 15th century (ca AD 1440). Here, we consider as "native forest" both the humid evergreen broadleaf laurel forest and other native forest types such as the Juniperus brevifolia- and Erica azorica-dominated forests. The Azorean laurisilva differs from that found on Madeira and on the Canary Islands as it includes just a single species of Lauraceae (Laurus azorica), although also featuring several species of sclerophyllous and microphyllous trees and shrubs (e.g. J. brevifolia and E. azorica), and luxuriant bryophyte communities, covering all available substrata (Gabriel and Bates 2005).

The destruction of the native forest in the Azores has followed a clear temporal sequence. At the time of human colonization the archipelago was almost entirely covered by forest (ca AD 1440) (Martins 1993, Silveira 2007). By $300 \mathrm{yr}$ ago (ca AD 1700) human activities had restricted the native forest in most islands to areas above $300 \mathrm{~m}$ a.s.l. and by ca $\mathrm{AD} 1850$, areas with native forest were mainly present above $500 \mathrm{~m}$ a.s.l. (Silveira 2007). The development of an economy dependent on milk production during the last decades of the 20th century drove a further reduction of native forest area, with the clearing of large fragments at mid- and high-altitude for pasture, further decreasing the native forest to its current extent of $2.5 \%$ of the total area of the archipelago $\left(<58 \mathrm{~km}^{2}\right.$ in total). Thus, in $<600 \mathrm{yr}$ $>95 \%$ of the original native forest has been destroyed (Gaspar 2007, Gaspar et al. 2008, Table 1). 


\section{Data}

As a result of the exhaustiveness of taxonomic work, the relative poorness of the Azorean fauna, and the intensive sampling during the last ten years (see Supplementary material for an analytical description of the sampling method), the Borges et al. (2005b) checklist (updated also with recent unpublished data) includes virtually all arthropod species native to the Azores, reported and described from 1859 (Drouët 1859) up to today, as well as an accurate account of their presence or absence in all the islands of the archipelago. The data for the Araneae, Hemiptera and Coleoptera are particularly comprehensive (Borges et al. 2005b, Borges and Wunderlich 2008, Cardoso et al. 2010). In this context, even if more species remain to be discovered from the islands in the future (e.g. Borges and Wunderlich 2008), we can reasonably regard each island as being currently proportionally equally well-sampled.

In 1998, 60 native species (excluding Crustacea, Acari, Collembola, Hymenoptera and Diptera) were known to be SIE. During 1999 and 2000, 64 transects were set up, covering all remnants of native forest in the Azorean islands (BALA project) (Borges et al. 2005a, Ribeiro et al. 2005, Table 1). Eight species out of the original 60 SIE were found in other islands, but also 13 new species were described, nine of them being SIE (Borges and Wunderlich 2008). During 2003 and 2004, 38 new transects were set up in the same forest remnants (Gaspar 2007, Gaspar et al. 2008). After this intensive additional round of surveys, only one further species previously thought to be a SIE was found in another island, demonstrating the high reliability of the current checklist at the island level.

Based on previous work (Borges and Brown 1999, Borges et al. 2005a, 2006, 2008, Ribeiro et al. 2005, Gaspar 2007, Borges and Wunderlich 2008, Gaspar et al. 2008) the endemic arthropods were classified as native forest dependent and non-forest dependent species (e.g. cave-adapted species, native grassland specialists, species also surviving in exotic forests or other man-made habitats). A species was considered forest-dependent (i.e. forest specialist) when $85 \%$ or more of its individuals have been collected in native vegetation (see Forest dependent endemic species in Supplementary material Table S1). Only the forest-dependent species endemic to the archipelago (59 species in total) were considered for further analyses; these species represent $56 \%$ of all the endemic species of the taxa considered. Despite the intensive survey effort recently carried out in anthropogenic habitats on some of the islands (Terceira, Pico, Graciosa and Santa Maria; Borges and Brown 1999, Borges et al. 2005a, 2006, 2008, Borges and Wunderlich 2008; see also Supplementary material), none of the species considered as a native forest endemic here has been found to have large populations in any other type of land use $(<15 \%$ of their total numbers of individuals, after standardising for sampling effort; see details in Supplementary material Table S1). The completeness and comparability of these surveys was verified using a number of sampling effort algorithms (see Sampling effort analysis in the Supplementary material).

The respective species lists of endemic forest specialists for the above three taxa were extracted for the areas of native forest corresponding to four points in time (below). This step was undertaken using SQL-based queries on the ATLANTIS-Azores database by means of the Atlantis Tierra 2.0 software (Zurita and Arechavaleta 2003, Borges et al. 2005b, Table 2). The ATLANTIS-Azores database includes an exhaustive checklist created by many taxonomists, who have recently performed a detailed revision of the taxonomic status of many species, identified many synonyms and improved the list of Azorean arthropods (Borges et al. 2005b). This database includes the spatial distribution of all recorded species specimens in a $500 \times$ $500 \mathrm{~m}$ grid, based on both literature and unpublished field data, hence allowing us to obtain the list of species for any region within any of the islands. Here we extracted four different species lists for each taxon, each one of them chosen to correspond to the extent of native forest at four known points in time before and since human colonization (Table 1; Fig. 2 with the island of Terceira as an illustration). They were as follows: a) for the total area of each island, i.e. all known forest specialist species reported from the island. This reflects the near $100 \%$ forest cover of the islands before the arrival of humans; AD 1440, herein $\mathrm{T}_{1}$. b) For areas above $300 \mathrm{~m}$, including only those species reported above this elevational limit and corresponding to the extent of the native forest ca $\mathrm{AD} 1700, \mathrm{~T}_{2}$. c) For areas above $500 \mathrm{~m}$, the extent of the native forest at ca $\mathrm{AD} 1850, \mathrm{~T}_{3}$. d) for the present area occupied by native forest, including only those species currently reported from native forest remnants within each island, $\mathrm{AD} 2000, \mathrm{~T}_{4}$.

The slight differences in the number of species denoted for (a), (b) and (c) are due to the fact that some species have been recorded only from the lowland areas which have been sequentially lost over time. As Raheem et al. (2009) have recently shown, the influence of pre-fragmentation patterns of species turnover can persist despite habitat loss and fragmentation, with the spatial pattern in species distribution before disturbance persisting to the present. Thus, we avoided considering each island as a priori biogeographically homogeneous before habitat destruction, in terms of species distribution in the different elevational zones considered. The differences between the species number for the total island area (a) and for the current extent of the native forest (d) (Table 2) are due to the inclusion in (a) of historical records of species presences in low and mid altitudes where the native forest is now absent. This means that if a species has been reported in the past from a lowland area where the native forest is now absent and this species is not found in any of the areas currently covered by native forest, the species was included in list (a) but not in list (d). Thus, for this latter category we are not following the simple elevational criterion used for (b) and (c) but we are instead using the actual distribution of the native forest patches.

The current area of native forests for all the islands (Table 1) was estimated based on digital aerial photography of the islands and field work (Gaspar 2007, Gaspar et al. 2008).

\section{Calculation of extinction debt}

To explore the impact of native forest destruction on current levels of endemic arthropod species richness, we 


\section{IBS SPECIAL ISSUE}

Table 1. Basic characteristics of the islands of the Azores (main source: Borges and Hortal 2009; see also Methods). Latitude and longitude refer to the centre of the island, and are given in decimal degrees. Total area of the island approximates the forest cover before the arrival of humans; $A D 1440, T_{1}$; area above $300 \mathrm{~m}$ corresponds to the extent of the native forest ca AD 1700, $\mathrm{T}_{2}$; area above $500 \mathrm{~m}$, the extent of the native forest ca AD $1850, \mathrm{~T}_{3}$; and the present area of forest remnants is for AD 2000, $\mathrm{T}_{4}$ - - : absence of native forest: *currently there is no primary native forest on Graciosa and Corvo Islands. On Graciosa only a very small patch of secondary native vegetation occurs; this patch is dominated by small-sized Erica azorica, an early successional endemic shrub.

\begin{tabular}{|c|c|c|c|c|c|c|c|c|}
\hline Island & $\stackrel{\text { Latitude }}{{ }^{\circ} \mathrm{N}}$ & $\begin{array}{l}\text { Longitude } \\
{ }^{W}\end{array}$ & $\begin{array}{l}\text { Altitude } \\
(\mathrm{m})\end{array}$ & $\begin{array}{l}\text { Total area of island } \\
\left(\mathrm{km}^{2}\right), \mathrm{T}_{1}\end{array}$ & $\begin{array}{c}\text { Area above } 300 \mathrm{~m} \\
\left(\mathrm{~km}^{2}\right), \mathrm{T}_{2}\end{array}$ & $\begin{array}{c}\text { Area above } 500 \mathrm{~m} \\
\left(\mathrm{~km}^{2}\right), \mathrm{T}_{3}\end{array}$ & $\begin{array}{l}\text { Present area of forest } \\
\text { remnants }\left(\mathrm{km}^{2}\right), \mathrm{T}_{4}\end{array}$ & $\begin{array}{l}\text { Maximum } \\
\text { age (Ma) }\end{array}$ \\
\hline Graciosa & 39.0 & 27.6 & 398 & 62 & 3.48 & - & _* & 2.50 \\
\hline Corvo & 39.4 & 31.0 & 718 & 17 & 9.33 & 5.44 & _* & 0.71 \\
\hline Santa Maria & 36.9 & 25.1 & 587 & 97 & 13.19 & 0.21 & 0.09 & 8.12 \\
\hline Faial & 38.6 & 28.5 & 1043 & 172 & 80.45 & 36.59 & 2.26 & 0.73 \\
\hline São Jorge & 38.7 & 27.9 & 1053 & 246 & 170.56 & 90.35 & 2.93 & 0.55 \\
\hline São Miguel & 37.7 & 25.5 & 1103 & 757 & 352.39 & 186.02 & 3.31 & 4.01 \\
\hline Pico & 38.5 & 28.2 & 2351 & 433 & 261.66 & 188.30 & 9.52 & 0.25 \\
\hline Flores & 39.4 & 30.9 & 915 & 142 & 95.18 & 52.58 & 15.71 & 2.90 \\
\hline Terceira & 38.7 & 27.2 & 1023 & 402 & 177.60 & 70.09 & 23.45 & 3.52 \\
\hline Total & & & & 2328 & 1163.84 & 629.58 & 57.27 & \\
\hline
\end{tabular}

Table 2. The number of forest-dependent endemic arthropod species in the four different habitat areas, corresponding to the extent of native forest at four known points in time, before and following human colonization (Supplementary material Table S2 and Methods for details).

\begin{tabular}{|c|c|c|c|c|c|c|c|c|c|c|c|c|}
\hline \multirow[t]{2}{*}{ Island } & \multicolumn{4}{|c|}{ Coleoptera } & \multicolumn{4}{|c|}{ Araneae } & \multicolumn{4}{|c|}{ Hemiptera } \\
\hline & $\begin{array}{c}\text { Total area, } \\
\mathrm{T}_{1}\end{array}$ & $\begin{array}{c}\text { Area }>300 \mathrm{~m}, \\
\mathrm{~T}_{2}\end{array}$ & $\begin{array}{c}\text { Area }>500 \mathrm{~m}, \\
\mathrm{~T}_{3}\end{array}$ & $\begin{array}{c}\text { Present area, } \\
\mathrm{T}_{4}\end{array}$ & $\begin{array}{c}\text { Total area, } \\
\mathrm{T}_{1}\end{array}$ & $\begin{array}{c}\text { Area }>300 \mathrm{~m}, \\
\mathrm{~T}_{2}\end{array}$ & $\begin{array}{c}\text { Area }>500 \mathrm{~m}, \\
\mathrm{~T}_{3}\end{array}$ & $\begin{array}{c}\text { Present area, } \\
\mathrm{T}_{4}\end{array}$ & $\begin{array}{c}\text { Total area, } \\
\mathrm{T}_{1}\end{array}$ & $\begin{array}{c}\text { Area }>300 \mathrm{~m}, \\
\mathrm{~T}_{2}\end{array}$ & $\begin{array}{c}\text { Area }>500 \mathrm{~m}, \\
\mathrm{~T}_{3}\end{array}$ & $\begin{array}{c}\text { Present area, } \\
\mathrm{T}_{4}\end{array}$ \\
\hline Graciosa & 2 & 2 & - & - & 3 & 2 & - & - & 3 & 1 & - & - \\
\hline Corvo & 1 & 1 & 1 & - & 0 & 0 & 0 & - & 2 & 2 & 2 & - \\
\hline Flores & 8 & 7 & 6 & 6 & 11 & 11 & 11 & 10 & 5 & 5 & 4 & 3 \\
\hline Faial & 4 & 3 & 3 & 3 & 8 & 8 & 7 & 7 & 5 & 5 & 5 & 3 \\
\hline Pico & 14 & 13 & 13 & 13 & 10 & 10 & 10 & 10 & 4 & 4 & 4 & 4 \\
\hline São Jorge & 4 & 4 & 4 & 4 & 11 & 11 & 11 & 11 & 6 & 6 & 6 & 4 \\
\hline Terceira & 11 & 10 & 9 & 9 & 11 & 11 & 11 & 10 & 8 & 7 & 7 & 5 \\
\hline São Miguel & 17 & 17 & 11 & 11 & 11 & 10 & 9 & 9 & 6 & 5 & 5 & 5 \\
\hline Santa Maria & 14 & 13 & 12 & 12 & 7 & 7 & 6 & 6 & 3 & 3 & 3 & 3 \\
\hline
\end{tabular}


assumed a multiple linear relationship between species number (S), area (A) and the geological age of each island (G), ) i.e. $\log S=b_{1}+b_{2} \log A+b_{3} G$, for the endemic forest-dependent species of Araneae, Hemiptera and Coleoptera. For number of species and area we used the conventional logarithmic transformations $\left(\log _{10}\right)$ to estimate the equation parameters (Borges and Brown 1999, Borges and Hortal 2009, cf. Rosenzweig 2001). For the particular case of the single island, where the number of Araneae species was zero we used the conventional practice of raising the values for all islands by 0.5 .

Inclusion of island age (Supplementary material) follows previous theoretical and empirical work showing that age can influence the evolutionary dynamics of oceanic islands, as reflected in levels of endemism (Whittaker et al. 2008, Borges and Hortal 2009). Including island age means that we do not assume that the islands were in a pure "ecological" immigration-extinction equilibrium prior to human colonization. Instead, the number of endemic forest species prior to human colonization is assumed to be a longer-term outcome of immigration, speciation and extinction dynamics.

We calculated our species-area-age relationships using four different "habitat areas" corresponding to the extent of native forest at four known points in time: $\mathrm{AD} 1440$ (total area), AD 1700 (area above $300 \mathrm{~m}$ ), AD 1850 (above $500 \mathrm{~m}$ ) and AD 2000 (current extent) (see above). If "relaxation" of species numbers has not yet taken place or is incomplete (i.e. an extinction debt remains) then the best fitting species-area-age model will correspond to the remaining area of forest at some past time. However, which "past time" may not be the same for each taxon due to differences in their ecology and life history. Additionally, we tested the effectiveness of the applied model against a number of different models, e.g. including measures of island elevation, log-transformed age values, and considering quadratic models of geological age, i.e. $G+G^{2}$ (Whittaker et al. 2008).

An alternative explanation for the lack of relationship between the current extent of native forest and the number of forest dependent species is that larger islands originally had more species as a consequence of their larger area. Thus, due to their larger species pool, more species would be expected to be found in fragments within larger islands. To test this mechanism we evaluated the relationship between the number of the archipelagic endemic species of the three taxa considered here and the total area of each island and compared its explanatory power with the respective speciesarea-age relationship. If larger islands have more species, then the species-area model will be the best for the species richness of the endemic taxa. We also tested the predictive accuracy of the two species-area-age models (for the total area and the area above $300 \mathrm{~m}$ ) by testing the correlation between the observed and the predicted number of species.

Finally, in order to evaluate our predictions, we compare the average species abundance per transect (i.e. average number of individuals of archipelagic endemic forestdependent species per transect) of Graciosa Island with the rest of the islands of the archipelago. Currently there is no primary native forest on Graciosa; only a very small patch of secondary native vegetation occurs, dominated by small-sized Erica azorica, an early successional endemic shrub. Hence we predict that the surviving forest-dependent species that are present in several islands will show smaller abundances within transects on Graciosa, indicative of a progressive reduction of their populations towards extinction. All analyses were carried out using STATISTICA 6.1 (StatSoft 2003).

\section{Results}

For the total island area and the area above $300 \mathrm{~m}$, the species-area-age model applied was significant $(\mathrm{p}<0.05)$ for each of the arthropod taxa considered (Table 3), with most of the explained variance attributable to area. However, for the area above $500 \mathrm{~m}$ and the present area covered by native forest, neither the species-area-age relationships nor the respective species-area relationships were statistically significant for any of the three taxa considered (Supplementary material Table S2). We thus used the first two benchmark relationships, for total area $\left(\sim \mathrm{AD} 1440, \mathrm{~T}_{1}\right)$ and area above $300 \mathrm{~m}\left(\sim \mathrm{AD} 1700, \mathrm{~T}_{2}\right)$ (Fig. 1 and 2B), to represent the baseline conditions for estimation of current extinction debt. Hence, we used the parameters estimated for the total area of the islands (Pred. 1; Table 4), and that of the area above $300 \mathrm{~m}$ (Pred. 2 ; Table 4) to estimate the number of endemic forest arthropods that "should" be present and, by direct comparison with the number of extant species, derive the number of species to go extinct (i.e. the extinction debt) for each taxon (Table 4 and Supplementary material S3).

For all three arthropod taxa considered, our results clearly indicate that the majority of the endemic forestdependent species are expected to go extinct in time, especially on those islands on which the native forest has been restricted to small areas, namely Santa Maria, São Miguel, São Jorge and Faial, or on which it has been totally removed, namely Graciosa and Corvo (Table 1 and 4). Terceira, the island with the largest remnants of native

Table 3. The species-area-age equations used for predicting extinctions. S: number of forest-dependent archipelagic endemic species; A: area; G: geological age; b: standard error for non-standardized regression coefficients (see Methods for details). The degrees of freedom (DF), F and p-values are also presented. For all the models tested see Supplementary material Table S2.

\begin{tabular}{|c|c|c|c|c|c|c|c|c|}
\hline Taxon/island area & Equation & SE intercept & $\mathrm{SE} \mathrm{b}_{\mathrm{A}}$ & $S E b_{G}$ & DF & $\mathrm{R}^{2}$ & F-value & p-value \\
\hline Coleoptera (total area) & $\log S=-0.915+0.678 \times \log A+0.076 \times G$ & 0.288 & 0.126 & 0.025 & 2.6 & 0.87 & 20.14 & $<0.01$ \\
\hline Coleoptera (>300 m) & $\log S=-0.383+0.471 \times \log A+0.116 \times G$ & 0.198 & 0.092 & 0.026 & 2.6 & 0.86 & 18.78 & $<0.01$ \\
\hline Araneae (total area) & $\log S=-0.979+0.780 \times \log A+0.026 \times G$ & 0.189 & 0.170 & 0.03 & 2.6 & 0.79 & 11.06 & 0.01 \\
\hline Araneae $(>300 \mathrm{~m})$ & $\log S=-0.318+0.531 \times \log A+0.067 \times G$ & 0.238 & 0.153 & 0.04 & 2.6 & 0.68 & 6.33 & 0.03 \\
\hline Hemiptera (total area) & $\log S=-0.060+0.321 \times \log A-0.007 \times G$ & 0.184 & 0.080 & 0.016 & 2.6 & 0.73 & 7.96 & 0.02 \\
\hline Hemiptera ( > $300 \mathrm{~m})$ & $\log S=-0.088+0.347 \times \log A+0.016 \times G$ & 0.146 & 0.067 & 0.019 & 2.6 & 0.82 & 13.27 & $<0.01$ \\
\hline
\end{tabular}



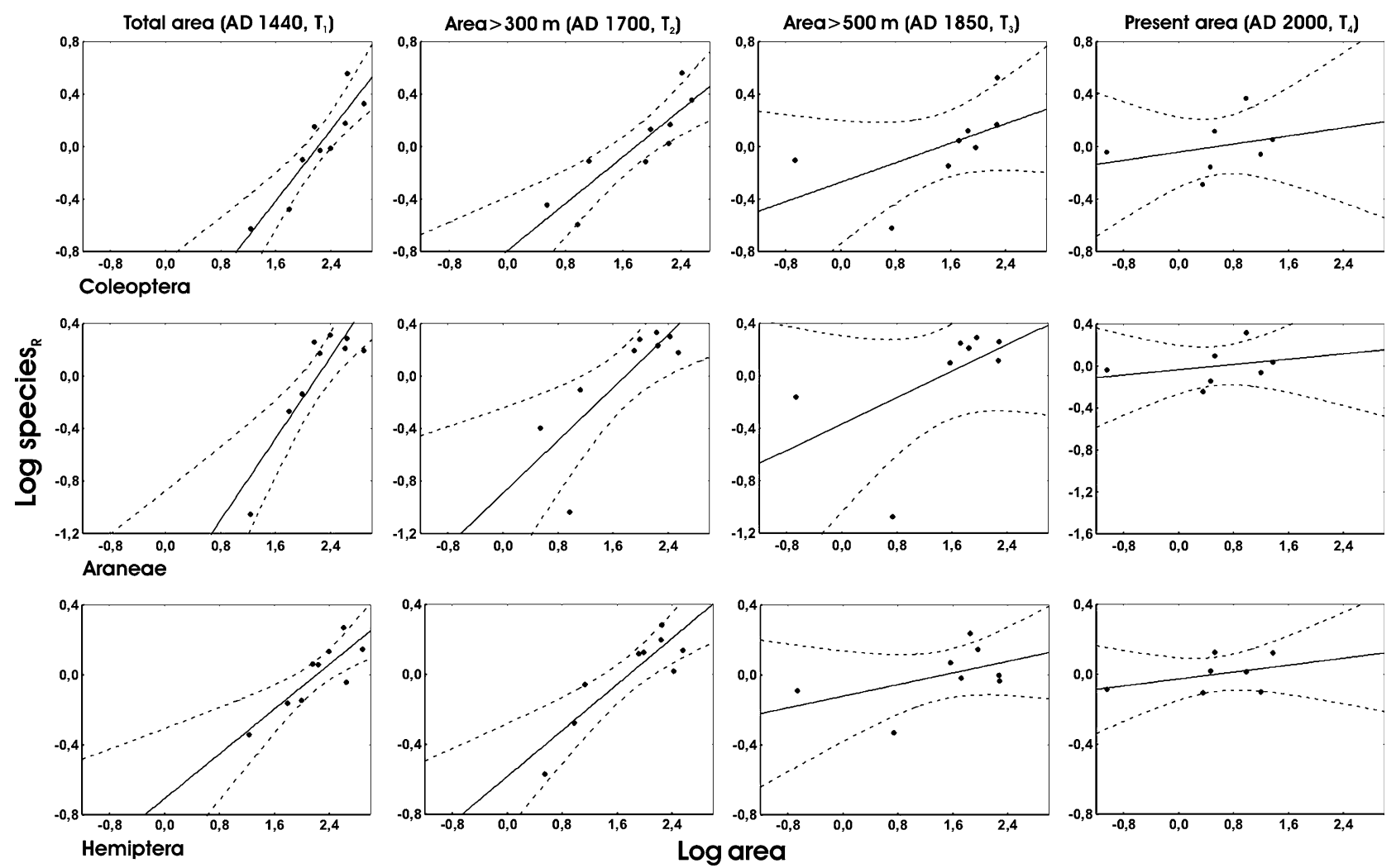

Figure 1. Species-area relationships for the endemic forest arthropods of the three groups studied (Coleoptera, Araneae, Hemiptera), for the areas of native forest corresponding to four known points in time (see text). In order to exclude the effect of island age on species richness, for purposes of visual representation we present the relationship between the residuals of the log (species)-age relationship, (i.e. geological age-independent richness) against $\log \left(\right.$ area $\mathrm{km}^{2}$ ). While the relationships for the total area (AD $\left.1440, \mathrm{~T}_{1}\right)$ and the area above $300 \mathrm{~m}\left(\mathrm{AD} 1700, \mathrm{~T}_{2}\right.$ ) were statistically significant for all taxa, for the area above $500 \mathrm{~m}\left(\mathrm{AD} 1850, \mathrm{~T}_{3}\right)$ and the present area of the native forest $\left(\mathrm{AD} 2000, \mathrm{~T}_{4}\right.$ ) they are not statistically significant for any taxon (see Supplementary material Table S2 for details). Solid lines are regression trend-lines, and dashed lines are $95 \%$ confidence intervals. Non-significant relationships are shown here for purposes of comparison.

forest, has the smallest number of predicted future extinctions. The estimated proportion of extinctions per island varies from 50 to $99 \%$ for Coleoptera, 60 to $99.5 \%$ for Araneae and 49 to $85 \%$ for Hemiptera. Amongst the three taxa, Hemiptera are at the lowest overall risk of extinction. The mean predicted percentage of extinctions for all the islands is: Coleoptera, $91.56 \%( \pm 5.68 \%$; Pred. 1$)$ and $74 \%$ ( $\pm 15.82 \%$; Pred. 2), Araneae, $94.81 \%$ ( $\pm 4.41 \%$; Pred. 1$)$ and $80.81 \%( \pm 10.73 \%$; Pred. 2$)$, and Hemiptera, $68.56 \%$ $( \pm 12.42 \%$; Pred. 1$)$ and $67 \%( \pm 13.06 \%$; Pred. 2$)$. These projections are in accordance with the distribution of the taxa across the island group since the percentage of endemic forest-dependent species present in three or fewer islands is $72 \%$ for Coleoptera, $47 \%$ for Araneae and 36\% for Hemiptera.

In the multiple regression models applied, the age parameter was statistically significant only in the case of Coleoptera; hence, when it was excluded from the models applied for spiders and Hemiptera, the predictions remained the same (without any statistically significant difference for the values presented). However, we applied the species-area-age model in all cases for purposes of comparison (Table 3). Note that this does not affect the statistical significance of the relationships used, i.e. the relationships estimated based on the area above $500 \mathrm{~m}$ and the current area of the native forest remain statistically non-significant even when only area is considered (Supplementary material Table S2), and the calculated parameters remain statistically indistinguishable for the cases where age has no significant contribution (Supplementary material Table S2). Additionally, the models we report were always better, based on the adjusted $\mathrm{R}^{2}$ values and the Akaike's information criterion values (AIC), than were models considering elevation or quadratic age (results not shown).

The species-area model for the archipelagic endemic species was the best model (i.e. lower value of AIC) only for Araneae (see Alternative mechanism in Supplementary material and Table S4), indicating that at least for Coleoptera and Hemiptera, the hypothesis that larger islands have more species, independent of the current area of the native forests, can be ruled out.

The general pattern arising from the cross-checking of the predictive accuracy of the two species-area-age models used (Supplementary material Table S5) demonstrates that using the parameter estimations from the species-area-age model of the areas $>300 \mathrm{~m}$ over-predicts the number of species that are present when applied to the total area of the islands, while the use of the parameters arising from the species-area-age model for the total area leads to an underestimation of the species present in areas above $300 \mathrm{~m}$ (Supplementary material Table S5 and further discussion in the Supplementary material). In all cases 


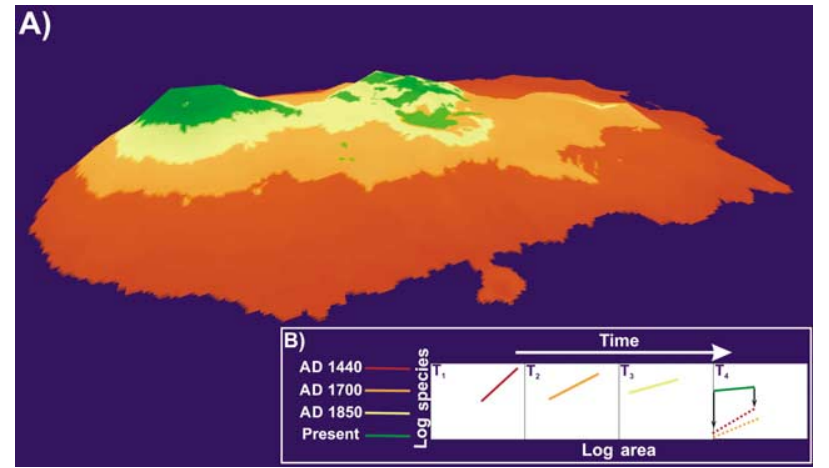

Figure 2. The sequential reduction of the native forest and the respective species-area relationships. (A) The elevational distribution of native forest in historical times for the island of Terceira (Azores; using Atlantis Tierra 2.0 software and Silveira 2007). Red (total area, $\mathrm{T}_{1}$ ): before human occupation, (almost complete coverage of island's area); orange (area $>300 \mathrm{~m}, \mathrm{~T}_{2}$ ): ca $300 \mathrm{yr}$ ago $(300-500 \mathrm{~m})$; yellow (area $>500, \mathrm{~T}_{3}$ ): ca $160 \mathrm{yr}$ ago (above $500 \mathrm{~m}$ ); green (present area, $\mathrm{T}_{4}$ ): current distribution. (B) A schematic representation of the effects of the sequential reduction of the native forest on the species-area relationships of endemic forest arthropods. The dashed line in $\mathrm{T}_{4}$ represents the future speciesarea relationships, extrapolated from $T_{1}$ and $T_{2}$ (see text). The magnitude of the extinction debt is represented by the difference between current species richness (solid green line) and the future predictions (dashed lines).

the Durbin-Watson test, applied to detect the presence of autocorrelation, indicates that the residuals are not positively autocorrelated, except for the Araneae $>300 \mathrm{~m}$ dataset, for which the test is not conclusive (Supplementary material Table S6) and the coefficient of determination $\left(\mathrm{R}^{2}\right)$ of the relationship between observed and predicted number of species (log-transformed values) was higher than 0.65 .

The results of the comparison of species average abundance on Graciosa Island with the rest of the islands, where native forest still exists, clearly indicate that for the clear majority of the eight species for which available data exists, there is a clear pattern of lower abundances in Graciosa Island (Supplementary material Table S7).

\section{Discussion}

Brook et al. (2003), studying a wide range of terrestrial and freshwater taxa from Singapore, inferred that $34-87 \%$ of species identified as forest specialists had gone extinct following deforestation in Singapore. They referred to these as catastrophic extinctions and warned that $13-42 \%$ of regional populations in south east Asia will be lost over the next century due to habitat loss, in the absence of remedial action. Our estimates for the magnitude of the extinction debt among forest-dependent endemic arthropods in the Azores are even higher than these startling figures and suggest that more than half of the extant species might eventually be driven to extinction due to habitat loss; a habitat loss which is almost complete ( $>95 \%$ of the original extent of the native forest) and has occurred in $<600 \mathrm{yr}$. The severity of the deforestation, both in terms of the spatial extent and the temporal scale, has clearly reduced

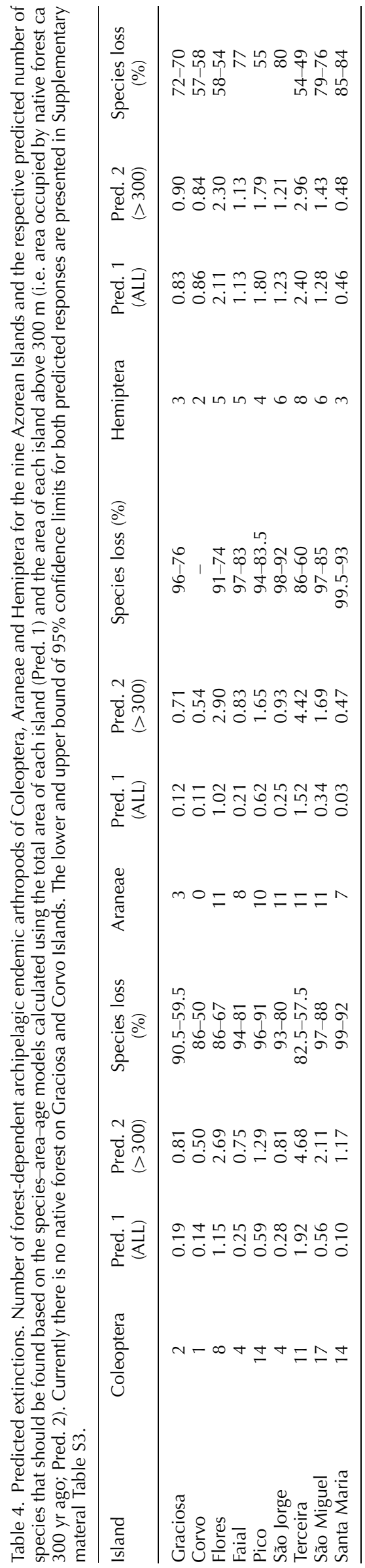


the opportunities for forest-dependent species to cope with the changes in their environment.

At face value, these figures constitute a powerful warning to island conservationists that the worst of the extinction crisis is by no means over. Furthermore, in spite of the fact that some archipelagic endemic species may benefit from a degree of population reinforcement between habitat fragments or islands (see also Borges et al. 2008), the parallel reduction of the native forest across all islands in the last $600 \mathrm{yr}$ has greatly diminished the probability of such source-sink dynamics rescuing species from global extinction. Hence, we would also anticipate a correspondingly large number of archipelagic-scale species extinctions for Azorean endemic arthropods in the future as the extinction debt is settled.

Amongst the three studied taxa, our analyses suggest that Araneae and Coleoptera are at greater risk of extinction per island, compared to Hemiptera. This may be partially related to the ecological characteristics and requirements of the species in each group, with Hemiptera typically exhibiting higher dispersal abilities and having a smaller proportion of species endemic to a single island (SIE: 6\%). In contrast, both Araneae and Coleoptera have high proportions of SIEs, 19.4 and $18.9 \%$ respectively. Additionally, spiders, the most important arthropod predators in the Azores, are expected to be relatively intolerant to the destruction and disturbance of natural forests on these islands (Cardoso et al. 2007, 2010) as shown for other high trophic level taxa (Whittaker and Fernández-Palacios 2007). We recognise that other processes may be involved in the extinctions to come apart from habitat loss, but at the same time these area-based models can offer an effective descriptor of the combined effects of other causes (see also Hanski et al. 2007, Yaacobi et al. 2007). One such additional factor is undoubtedly the significant pressure exerted by exotic species (Blackburn et al. 2004, Whittaker and Fernández-Palacios 2007), which already comprise $58 \%$ of the total Azorean arthropod fauna (68\% of Araneae, $60 \%$ of Coleoptera and $47 \%$ of Hemiptera, Borges et al. 2005b, 2006)

The figures that we report here are likely to be more accurate than previous predictions because we have focused our attention on endemic forest species that have evolved in and are only found in association with the native forest. Endemic forest dependent species are unlikely to show a range expansion to anthropogenic habitats under land-use changes. Hence, we avoid additional "noise" caused by generalist species that may well be able to survive in other (i.e. anthropogenic) habitats. For example, there is no evidence that the endemic forest arthropods on Terceira can establish viable populations within other forest or vegetation types on the island (Borges and Wunderlich 2008, Borges et al. 2008, see also Methods). Furthermore, we base our predictions on two baseline curves, and not on a single one as usually applied, an approach providing fairly conservative estimates of the present extinction debt, taking into account the crude but reasonably well-founded habitat distributional data available. However, it should also be recognised that the projected extinctions arising from the use of the species-area models involve several uncertainties (May et al. 1995, Lewis 2006, Vellend et al. 2006, Whittaker and Fernández-Palacios 2007, Kuussaari et al.
2009, Ladle 2009) and can never completely replace species-level assessments for the identification of extinction threat (Kotiaho et al. 2005, Whittaker et al. 2005, Kuussaari et al. 2009). Nevertheless, for many species of conservation concern the collection of appropriately detailed information is an unrealistic target. It is therefore important that we develop more realistic indirect measures and theoretical projections of extinctions, based on as pragmatic a set of assumptions as possible (Heywood et al. 1994, May et al. 1995, Whittaker et al. 2005). Here, by using taxon-specific z-values derived from speciesarea relationships of the same taxon in the same island system, we would argue that our extinction estimates are likely to prove more realistic and robust than previous analyses (see Yaacobi et al. 2007 for a similar example on habitat islands).

It is highly probable that since the original settlement of humans on the Azores a number of arthropods and other poorly known taxa have already become extinct due to deforestation (cf. Brook et al. 2003, Hanski et al. 2007, Cardoso et al. 2010). Thus, given that a large fraction of the island's forest had already been cleared before the first reliable standardized sampling (Borges et al. 2005a, 2006, 2008, Ribeiro et al. 2005, Gaspar 2007, Gaspar et al. 2008, Borges and Wunderlich 2008), the extinction of species most sensitive to disturbance probably went unrecorded (Cardoso et al. 2010). In point of fact, at least five SIE beetle species (Bradycellus chavesi, Calathus extensicollis, Calathus vicenteorum, Nesotes azorica, Ocydromus derelictus), recorded early in the 20th century, have not been recorded since 1965 and might therefore be considered extinct (Borges et al. 2000). Moreover, many other SIEs are extremely rare and under threat (Borges et al. 2006), and are particularly scarce in standardized samples (Supplementary material Table S1 for Terceira Island). While seven individuals of Calathus lundbladi, an endemic species of São Miguel, were found in four traps during 1989, just one individual was collected in 120 traps in the 19992000 survey (Borges et al. 2005a). The case of Graciosa Island is in accord with the above (Supplementary material Table S7); although species abundance responses to forest loss and fragmentation can be strikingly idiosyncratic (Fahrig 2001), and phenomena like density compensation as a result of the extinction of competitors and/or predators cannot be excluded (Whittaker and Fernández-Palacios 2007; Supplementary material Table S7), the very small fragment of secondary native vegetation in Graciosa, which is highly disturbed, can be considered as the "last refuge" for the endemic forest-dependent species on that island. These species are already on an ecological trajectory towards extinction. Although, it is possible that some forest specialist species might be able to find a refuge in exotic forests (Supplementary material Table S1), the durability and viability of these populations are probably limited (Borges, unpubl.). Conclusively proving the extinction of a small arthropod species will be practically impossible within such a large area as the Azorean archipelago $\left(2328 \mathrm{~km}^{2}\right)$, but we concur with others (Hanski et al. 2009, Ladle 2009), that given the great importance of understanding the processes and rates of species extinctions, analyses based on indirect evidence can be informative. 
Precise estimation of the time to extinction of each species under threat remains an unrealistic aim, for it will vary from island to island and from species to species. The scarce available information suggests that delayed extinctions are more likely to occur in species with longer generation times, e.g. mammals as opposed to insects, (see review in Kuussaari et al. 2009), but recent studies on invertebrates (Raheem et al. 2009, Sodhi et al. 2009) have shown a resilience of some invertebrate species to the effects of forest loss; with many species requiring only very small areas to persist for extended periods (see also discussion in Samways 2006). These results suggest a need for caution in generalizing about relaxation and species loss based on data for ecologically different taxa, such as vertebrates and especially birds. Despite the extensive destruction of the Azorean native forest, the remaining network of patches within some of the islands and the overall remaining area in the archipelago might be sufficient for delaying relaxation for long periods of time or even sustain viable populations for some species. Hence, the time lag may be considerable, even for invertebrates of short life cycles.

We conclude that large-scale conservation efforts need to be implemented if the high extinction debt we have identified is to be deferred or avoided. Human-induced fragmentation, land-use changes and invasive species have already been identified as important threats to Azorean biodiversity (Martins 1993, Borges et al. 2000, 2006, Borges and Wunderlich 2008). Our analyses strongly reinforce this message: the conservation of the Azorean natural heritage, and that of many other oceanic islands, will largely depend on establishing an integrated large-scale strategy to manage both indigenous and non-indigenous species while simultaneously protecting the remnants of native habitat (i.e. forest in the Azorean context) and, ideally, increasing their extent. This point is corroborated by the case of the Azorean bullfinch Pyrrhula murina, an endemic passerine bird species confined to eastern São Miguel and living almost exclusively in the laurel forest. The species, locally abundant in the second half of 19th and early 20th century, has suffered through widespread loss of native forest and invasion by exotic vegetation, which has largely overrun the remaining patches of natural vegetation within the bullfinch's breeding range. This led to a dramatic decline, to $<100$ individuals, in the late 1970s. Following the implementation in 2003 of a five-year LIFE-Nature project, a central objective of which was to increase the habitat of the Azores bullfinch, mainly through promoting the regeneration of the laurel forest and the control of the exotic flora (Ramos 1996, 2005, Guimarães and Olmeda 2008), the population had increased to an estimated 400 pairs by the year 2006 (Guimarães and Olmeda 2008).

In the absence of focused and well-resourced interventions, the legacy of past and current deforestation on oceanic islands will be an inexorable process of biodiversity loss stretching well into the future. Many extant species may already have passed crucial thresholds of population size and/or genetic diversity that typically precede extinction, meaning that the species are becoming highly sensitive to demographic and environmental stochasticity (Schoener et al. 2003). The approach to estimating extinction debt outlined in this work may be suitable for application to many other analogous systems, including numerous oceanic archipelagos that have experienced anthropogenic habitat loss (Mueller-Dombois and Fosberg 1998, Rolett and Diamond 2004, Steadman 2006) and where the temporal sequence of habitat loss can be at least crudely estimated.

Acknowledgements - KAT, PAVB, RG and RJW designed the research, PAVB, CG, FD, LMAS, RG, CM, AMCS, IRA, PC, SPR, JH, ARMS, JAQ gathered the data, KAT, PAVB, EM, RJW and PC analysed the data, KAT, RJL, JH, PC, PAVB and RJW wrote the paper. All authors discussed the results and commented on the manuscript. We thank G. Mace, V. Brown, J. Sadler, S. Bhagwat, J. Lobo, A. Jiménez-Valverde, A. Parmakelis, S. Sfenthourakis, S. Meiri, attendees of the 2009 International Biogeography Society meeting in Merida, and especially Albert Phillimore and Andy Purvis for discussions and comments on previous drafts. We also thank Helmut Hillebrand, Robert Dunn and two anonymous referees for valuable comments on the manuscript. KAT was supported in this work by a Marie Curie Intra-European Fellowship Program (project "SPAR", 041095) held in the OUCE, by a FCT Fellowship (SFRH/BPD/44306/ 2008) and from the Academic Visitors Program of the NERC Centre for Population Biology. PAVB and RG worked on this project under the DRCT project M2.1.2/I/017/2007 and the EU projects INTERREGIII B “ATLÂNTICO” (2004-2006) and BIONATURA (2006-2008).

\section{References}

Blackburn, T. M. et al. 2004. Avian extinction and mammalian introductions on oceanic islands. - Science 305: 1955-1958.

Borges, P. A. V. and Brown, V. K. 1999. Effect of island geological age on the arthropod species richness of Azorean pastures. - Biol. J. Linn. Soc. 66: 373-410.

Borges, P. A. V. and Wunderlich, J. 2008. Spider biodiversity patterns and their conservation in the Azorean archipelago, with descriptions of new species. - Syst. Biodivers. 6: 249-282.

Borges, P. A. V. and Hortal, J. 2009. Time, area and isolation: factors driving the diversification of Azorean arthropods. - J. Biogeogr. 36: 178-191.

Borges, P. A. V. et al. 2000. Ranking the Azorean natural forest reserves for conservation using their endemic arthropods. - J. Insect Conserv. 4: 129-147.

Borges, P. A. V. et al. 2005a. Ranking protected areas in the Azores using standardised sampling of soil epigean arthropods. - Biodivers. Conserv. 14: 2029-2060.

Borges, P. A. V. et al. 2005b. A list of the terrestrial fauna (Mollusca and Arthropoda) and flora (Bryophyta, Pteridophyta and Spermatophyta) from the Azores. - Direcção Regional de Ambiente and Univ. Azores.

Borges, P. A. V. et al. 2006. Invasibility and species richness of island endemic arthropods: a general model of endemic vs. exotic species. - J. Biogeogr. 33: 169-187.

Borges, P. A. V. et al. 2008. Insect and spider rarity in an oceanic island (Terceira, Azores): true rare and pseudo-rare species. - In: Fattorini, S. (ed.), Insect ecology and conservation. Research Signpost, Kerala, India, pp. 47-69.

Brook, B. W. et al. 2003. Catastrophic extinctions follow deforestation in Singapore. - Nature 424: 420-423.

Brooks, T. M. et al. 1997. Deforestation predicts the number of threatened birds in insular southeast Asia. - Conserv. Biol. 11: 382-394.

Brooks, T. M. et al. 2002. Habitat loss and extinction in the hotspots of biodiversity. - Conserv. Biol. 16: 909-923.

Brooks, T. M. et al. 2006. Global biodiversity conservation priorities. - Science 313: 58-61. 
Cardoso, P. et al. 2007. Biotic integrity of the arthropod communities in the natural forests of Azores. - Biodivers. Conserv. 16: 2883-2901.

Cardoso, P. et al. 2010. Drivers of diversity in Macaronesian spiders and the role of species extinctions. - J. Biogeogr. 37, doi: 10.1111/j.1365-2699.2009.02264.x.

Darlington, P. J. 1957. Zoogeography: the geographical distribution of animals. - Wiley.

Diamond, J. M. 1989. The present, past and future of humancaused extinctions. - Phil. Trans. R. Soc. B 325: 469-477.

Drouët, H. 1859. Coléoptères Açoréens. - Rev. Mag. Zool. 11: 243-259.

Dunn, R. R. 2005. Modern insect extinctions, the neglected majority. - Conserv. Biol. 19: 1030-1036.

Fahrig, L. 2001. How much habitat is enough? - Biol. Conserv. 100: 65-74.

Fonseca, R. C. 2010. The silent mass extinction of insect herbivores in biodiversity hotspots. - Conserv. Biol. 23: $1507-1515$

Frutuoso, G. 1963. The sixth book on longing for the land. - Inst. Cultura de Ponta Delgada.

Gabriel, R. and Bates, J. W. 2005. Bryophyte community composition and habitat specificity in the natural forests of Terceira, Azores. - Plant Ecol. 177: 125-144.

Gaspar, C. S. 2007. Arthropod diversity and conservation planning in native forests of the Azores archipelago. - Ph.D. thesis, Univ. Sheffield.

Gaspar, C. et al. 2008. Diversity and distribution of arthropods in native forests of the Azores archipelago. - Arquipélago-Life Mar. Sci. 25: 1-30.

Guimarães, A. and Olmeda, C. 2008. Management of Natura 2000 habitat. $9360 *$ Macaronesian laurel forests (Laurus, Ocotea). - European Commission.

Hanski, I. et al. 2007. Deforestation and apparent extinctions of endemic forest beetles in Madagascar. - Biol. Lett. 3: 344-347.

Hanski, I. et al. 2009. Deforestation and tropical insect extinctions. - Biol. Lett. 5: 653-655.

Helm, A. et al. 2006. Slow response of plant species richness to habitat loss and fragmentation. - Ecol. Lett. 9: 72-77.

Heywood, V. H. et al. 1994. Uncertainties in extinction rates. - Nature 368: 105.

IUCN 2009. IUCN Red List of Threatened Species. Version 2009.2. - <www.iucnredlist.org >

Kotiaho, J. S. et al. 2005. Predicting the risk of extinction from shared ecological characteristics. - Proc. Nat. Acad. Sci. USA 102: 1963-1967.

Kuussaari, M. et al. 2009. Extinction debt: a challenge for biodiversity conservation. - Trends Ecol. Evol. 24: 564-571.

Ladle, R. J. 2009. Forecasting extinctions: uncertainties and limitations. - Diversity 1: 133-150.

Lande, R. 1993. Risks of population extinction from demographic and environmental stochasticity and random catastrophes. - Am. Nat. 142: 911-927.

Lewis, O. T. 2006. Climate change, species-area curves and the extinction crisis. - Phil. Trans. R. Soc. B 361: 163-171.

MacArthur, R. H. and Wilson, E. O. 1967. The theory of island biogeography. - Princeton Univ. Press.

Martins, A. M. F. 1993. The Azores - westernmost Europe: where evolution can be caught red-handed. - Bol. Mus. Municipal Funchal S2: 181-198.

May, R. M. et al. 1995. Assessing extinction rates. - In: Lawton, J. H. and May, R. M. (eds), Extinction rates. Oxford Univ. Press, pp. 1-24.

Download the Supplementary material as file E6203 from $<$ www.oikos.ekol.lu.se/appendix $>$.
McDonald, K. A. and Brown, J. H. 1992. Using montane mammals to model extinctions due to global change. - Conserv. Biol. 6: 409-415.

Mueller-Dombois, D. F. and Fosberg, F. R. 1998. Vegetation of the tropical Pacific islands. - Springer.

Paulay, G. 1994. Biodiversity on oceanic islands: its origin and extinction. - Am. Zool. 34: 134-144.

Pimm, S. L. and Askins, R. A. 1995. Forest losses predict bird extinctions in eastern North America. - Proc. Nat. Acad. Sci. USA 92: 9343-9347.

Pimm, S. L. et al. 1995. The future of biodiversity. - Science 269: 347-350.

Preston, F. W. 1962. The canonical distribution of commonness and rarity: part I. - Ecology 43: 185-215.

Raheem, D. C. et al. 2009. Fragmentation and pre-existing species turnover determines land-snail assemblages of tropical rain forest. - J. Biogeogr. 36: 1923-1938.

Ramos, J. A. 1996. Introduction of exotic tree species as a threat to the Azores bullfinch population. - J. Appl. Ecol. 33: 710-722.

Ramos, J. A. 2005. The Priolo and the natural altitude forest, 2nd ed. - Câmara Municipal de Nordeste.

Ribeiro, S. P. et al. 2005. Canopy insect herbivores in the Azorean laurisilva forests: key host plant species in a highly generalist insect community. - Ecography 28: 315-330.

Rolett, B. and Diamond, J. 2004. Environmental predictors of pre-European deforestation on Pacific islands. - Nature 431 443-446.

Rosenzweig, M. L. 2001. Loss of speciation rate will impoverish future diversity. - Proc. Nat. Acad. Sci. USA 98: 5404-5410.

Samways, M. J. 2006. Insect extinctions and insect survival. - Conserv. Biol. 20: 245-246.

Schoener, T. W. et al. 2003. Life-history models of extinction: a test with island spiders. - Am. Nat. 162: 558-573.

Silveira, L. M. A. 2007. Learning with history: interaction with nature during the human colonization in Terceira Island. - M.Sc. thesis, Univ. Azores.

Sodhi, N. S. et al. 2009. Insect extinctions on a small denuded Bornean island. - Biodivers. Conserv. 19: 485-490.

StatSoft 2003. STATISTICA (data analysis software system), version 6.1. - StatSoft, Tulsa, OK.

Steadman, D. W. 2006. Extinction and biogeography of tropical Pacific birds. - Univ. Chicago Press.

Thomas, C. D. et al. 2004. Extinction risk from climate change. - Nature 427: 145-148.

Tilman, D. et al. 1994. Habitat destruction and the extinction debt. - Nature 371: 65-66.

Vellend, M. et al. 2006. Extinction debt of forest plants persists for more than a century following habitat fragmentation. - Ecology 87: 542-548.

Whittaker, R. J. and Fernández-Palacios, J. M. 2007. Island biogeography: ecology, evolution, and conservation, 2nd ed. - Oxford Univ. Press.

Whittaker, R. J. et al. 2005. Conservation biogeography: assessment and prospect. - Divers. Distrib. 11: 3-23.

Whittaker, R. J. et al. 2008. A general dynamic theory of oceanic island biogeography. - J. Biogeogr. 35: 977-994.

Yaacobi, G. et al. 2007. Habitat fragmentation may not matter to species diversity. - Proc. R. Soc. B 274: 2409-2412.

Zurita, N. A. and Arechavaleta, M. 2003. Database of the biodiversity of the Canary Islands (Banco de datos de Biodiversidad de Canarias). - Bol. Soc. Entomol. Aragonesa 32: 293-294. 
Triantis, K. A., Borges, P. A. V., Ladle, R. J., Hortal, J., Cardoso, P., Gaspar, C., Dinis, F., Mendonça, E., Silveira, L. M. A., Gabriel, R., Melo, C., Santos, A. M. C., Amorim, I. R., Ribeiri, S., Serrano, A. R. M., Quartau, J. A. and Whittaker, R. J. 2010. Extinction debt on oceanic islands. - Ecography 33: 285-294.

\section{Supplementary material}

\section{Sampling method}

Epigaeic soil fauna were captured along $150 \mathrm{~m}$ long and $5 \mathrm{~m}$ wide transects. A linear direction was followed whenever possible but frequent deviations were needed due to uneven ground and very dense vegetation. Transects were marked with ropes to facilitate recognition. Along each transect, arthropods from the soil (mainly epigean) and herbaceous vegetation were surveyed with a set of pitfall traps, while arthropods from woody plant species were sampled using a beating tray. Pitfall traps consisted of plastic cups of 4.2 $\mathrm{cm}$ diameter and $7.8 \mathrm{~cm}$ depth. Thirty pitfall traps were used per transect. Half of the traps were filled with a non-attractive solution (ethylene glycol antifreeze solution), and the remaining with a general attractive solution (Turquin), prepared mainly with dark beer and some preservatives (for further details on the method and its application see Turquin 1973 and Borges et al. 2005). A few drops of liquid detergent were added to both solutions to reduce surface tension. The traps were sunk in the soil (with the rim at the surface level) every $5 \mathrm{~m}$, starting with a Turquin trap and alternating with the ethylene traps. They were protected from rain using a plastic plate, about $5 \mathrm{~cm}$ above surface level and fixed to the ground by two pieces of wire. The traps remained in the field for two weeks.

Canopy sampling was conducted during the period that pitfall traps remained in the field, when the vegetation was dry. A square $5 \mathrm{~m}$ wide was established every $15 \mathrm{~m}$ (10 squares in total per transect). In each square, a specimen of each of the three most abundant woody plant species was sampled. In most of the study sites, three species clearly dominated over the remaining plants and the choice was evident. However, in some transects, less than three were present and only those were considered. For each selected plant, a branch was chosen at random and a beating tray placed beneath. Five beatings were made using a stick. The tray consisted of a cloth inverted pyramid $1 \mathrm{~m}$ wide and $60 \mathrm{~cm}$ deep (adapted from Basset 1999), with a plastic bag at the end. Samples were sorted and the specimens preserved in $70 \%$ alcohol with glycerine.

During the summers of 1999 to 2004, a total of eighteen native forest fragments distributed across seven of the nine islands were sampled, involving 111 sites ( 3290 pitfall traps and 3337 beating samples) (see also Gaspar et al. 2008). In addition, in Terceira (see also Borges and Brown 1999, Cardoso et al. 2009), Pico (Borges and Brown 1999), Graciosa (Borges et al. 2006a) and Santa Maria (Borges unpubl.), an additional 64 sites were sampled (2970 pitfall traps), covering all the available habitat types present, i.e. natural grasslands, exotic forests, semi-natural pastures and intensively managed pastures.

\section{Sampling effort analysis}

The analyses carried out for this work required that habitats besides forests were thoroughly sampled, with similar values of

survey completeness (defined as the proportion of the estimated species that have already been observed). Only this way could we guarantee that the species considered as forest specialists were not wrongly classified as such, due to low sampling effort in other habitats. Here we discuss the case of the island of Terceira, based on data and analyses presented in Cardoso et al. (2009). In total, 81 sites/transects were sampled following the sampling method presented above. The sampling was intentionally biased towards natural forests, the habitats previously known to host higher numbers of endemic species and higher beta diversity. Hence, 45 sites were placed in natural forests, 9 in exotic forests, 11 in semi-natural pastures and 16 in intensively managed pastures (Cardoso et al. 2009). For each transect we calculated the estimated richness using the Chaol estimator (Chao 1984), with pitfall or beating samples as the effort unit. However, the estimates of species richness were far from reliable. As an alternative to completeness, we calculated the sampling intensity for each site, defined as the specimens to species ratio, a crude measure of sampling effort (Cardoso et al. 2008a, b). Additionally, we estimated the final slopes of overall species richness accumulation curves for all sites in the island (following the formula in Cardoso et al. 2008a, b). All curves were sample-based and rescaled to individuals, as suggested by Gotelli and Colwell (2001). The sampling intensity and slopes were both different between pasture and forest habitats, pastures presenting statistically significantly higher intensities (Mann-Whitney $\mathrm{p}<$ 0.011 in all paired comparisons) and lower slopes (Mann-Whitney $\mathrm{p}<0.037$ in all paired comparisons) than forests (see Cardoso et al. 2009). This indicates that effort was in fact higher outside forest sites, implying that our classification of forest species, at least of all species present in Terceira Island, was reliable.

\section{Forest dependent endemic species}

For defining forest-dependent species we followed a conservative threshold of $85 \%$ of the individuals of the species collected in native vegetation. For all the species considered as a native forest endemics here, a small number of individuals $(<15 \%$, after standardising for sampling effort, has been found in any other type of land use, in spite of the intensive survey effort recently carried out in anthropogenic habitats in some of the islands (Terceira, Pico, Graciosa and Santa Maria; Borges and Brown 1999, Borges et al. 2005, 2006a, b, Lopes et al. 2005, Borges and Wunderlich 2008).

Here we present the analytical data for the forest dependent endemic species of Araneae, Coleoptera and Hemiptera distributed on Terceira Island (Table S1). Although the decision for the characterization of a species as forest-dependent or not, has been based on the distribution of the total number of species' individuals across the archipelago, we validate the choices made using the information from Terceira, which is the best studied island. 
Table S1. The forest dependent archipelagic endemic species of Araneae, Coleoptera, and Hemiptera found on Terceira Island. For each species the total number of individuals collected in Terceira is given along with the percentage of individuals collected in native forest fragments. Since a different number of sites was sampled in native and non-native habitats (see Cardoso et al. 2009), the percentage has been calculated after standardising for the different number of sites involved.

\begin{tabular}{|c|c|c|c|}
\hline Group & Species & $\begin{array}{l}\text { Number of } \\
\text { individuals }\end{array}$ & $\begin{array}{l}\text { Percentage of individuals } \\
\text { found in native forest in Terceira }\end{array}$ \\
\hline \multirow[t]{11}{*}{ Araneae } & Savigniorrhipis acoreensis Wunderlich, 1992 & 5526 & $100 \%$ \\
\hline & Rugathodes acoreensis Wunderlich, 1992 & 1816 & $100 \%$ \\
\hline & Gibbaranea occidentalis Wunderlich, 1989 & 1458 & $100 \%$ \\
\hline & Sancus acoreensis (Wunderlich, 1992) & 1445 & $100 \%$ \\
\hline & Acorigone acoreensis (Wunderlich, 1992) & 104 & $98 \%$ \\
\hline & Lasaeola oceanica Simon, 1833 & 61 & $100 \%$ \\
\hline & Walckenaeria grandis (Wunderlich, 1992) & 42 & $100 \%$ \\
\hline & Minicia floresensis Wunderlich, 1992 & 28 & $100 \%$ \\
\hline & Porrhomma borgesi Wunderlich, 2008 & 29 & $89 \%$ \\
\hline & ${ }^{*}$ Neon acoreensis Wunderlich, 2008 & 9 & $68 \%$ \\
\hline & Typhochrestus acoreensis Wunderlich, 1992 & 1 & $100 \%$ \\
\hline \multirow[t]{11}{*}{ Coleoptera } & Trechus terrabravensis Borges, Serrano \& Amorim, 2004 & 329 & $100 \%$ \\
\hline & Cedrorum azoricus azoricus Borges \& Serrano, 1993 & 270 & $100 \%$ \\
\hline & Alestrus dolosus (Crotch, 1867) & 115 & $100 \%$ \\
\hline & Laparocerus azoricus Drouet, 1859 & 112 & $99 \%$ \\
\hline & Atheta dryochares Israelson, 1985 & 16 & $100 \%$ \\
\hline & Pseudechinosoma nodosum Hustache, 1936 & 4 & $100 \%$ \\
\hline & Atlantocis gillerforsi Israelson, 1986 & 2 & $100 \%$ \\
\hline & Phloeosinus gillerforsi Bright, 1987 & 2 & $100 \%$ \\
\hline & Athous azoricus Platia \& Gudenzi, 2002 & 1 & $100 \%$ \\
\hline & Phloeostiba azorica (Fauvel, 1900) & 1 & $100 \%$ \\
\hline & $\dagger$ Tarphius azoricus Gillerfors, 1986 & 1 & $0 \%$ \\
\hline \multirow[t]{8}{*}{ Hemiptera } & Cixius azoterceirae Remane \& Asche, 1979 & 3471 & $100 \%$ \\
\hline & Strophingia harteni Hodkinson, 1981 & 1087 & $100 \%$ \\
\hline & Pinalitus oromii J. Ribes 1992 & 686 & $100 \%$ \\
\hline & Aphrodes hamiltoni Quartau \& Borges, 2003 & 282 & $98 \%$ \\
\hline & Cixius azoricus azoricus Lindberg, 1954 & 21 & $100 \%$ \\
\hline & Eupteryx azorica Ribaut, 1941 & 6 & $100 \%$ \\
\hline & Javesella azorica Remane, 1975 & 1 & $100 \%$ \\
\hline & Orthotylus junipericola attilioi J. Ribes \& Borges, 2001 & 1 & $100 \%$ \\
\hline
\end{tabular}

* Neon acoreensis is a newly described species present in seven islands of the Azores (Borges and Wunderlich 2008). Out of the 15 known individuals of the species collected so far across the islands, only 2 have been found in non-native habitats in Terceira Island. We regard these specimens as most probably belonging to sink "populations" sourced from the nearby native forest fragments. Thus, we have considered it as a forest-dependent species.

$\dagger$ Tarphius azoricus: Tarphius is one of the most diverse insect genera found in the Azores, with eight endemic species, and they are clearly dependent on native vegetation (Borges et al. 2005, Gaspar et al. 2008). The species is almost exclusively found within native forest in the rest of the Azorean Islands and thus has been assigned as forest dependent. The fact that in Terceira the only individual belonging to Tarphius azoricus was found in an isolated small fragment of mixed exotic forest surrounded by intensive pastures and located in the older part of the island is a clear indication that this species is highly endangered in this island. 


\section{Calculation of extinction debt}

Table S2. The species-area-age equations used and the respective species-area equations. S: number of forest-dependent archipelagic endemic species; A: area; G: geological age; SE b: standard error for non-standardized regression coefficients (see Methods for details). The degrees of freedom (DF), F and p-values are also presented. Statistically significant relationships are highlighted in bold.

It is not always clear which estimate of island age is most appropriate in biological terms, especially when different taxa are considered (Whittaker et al. 2008). Our results are based on the estimated age of origin (maximum age) of each of the islands because this is more or less agreed upon (Borges and Hortal 2009) and because this provides a common framework for analysis.

\begin{tabular}{|c|c|c|c|c|c|c|c|c|}
\hline Taxon/island area & Equation & $\begin{array}{c}\text { SE } \\
\text { intercept }\end{array}$ & $\mathrm{SE}_{\mathrm{A}}$ & $\mathrm{SE}_{\mathrm{G}}$ & $\mathrm{DF}$ & $\mathrm{R}^{2}$ & F-value & $\mathrm{p}$-value \\
\hline \multirow[t]{2}{*}{ Coleoptera (total area) } & $\log S=-0.915+0.678 \times \log A+0.076 \times G$ & 0.288 & 0.126 & 0.025 & 2.6 & 0.87 & 20.14 & $<0.01$ \\
\hline & $\log S=-0.771+0.699 \times \log A$ & 0.418 & 0.185 & - & 1.7 & 0.67 & 14.28 & $<0.01$ \\
\hline \multirow[t]{2}{*}{ Coleoptera (>300 m) } & $\log S=-0.383+0.471 \times \log A+0.116 \times G$ & 0.198 & 0.092 & 0.026 & 2.6 & 0.86 & 18.78 & $<0.01$ \\
\hline & $\log S=0.068+0.380 \times \log A$ & 0.324 & 0.171 & - & 1.7 & 0.42 & 4.97 & 0.06 \\
\hline \multirow[t]{2}{*}{ Coleoptera $(>500 \mathrm{~m})$} & $\log S=-0.103+0.324 \times \log A+0.154 \times G$ & 0.299 & 0.129 & 0.047 & 2.5 & 0.69 & 5.30 & 0.06 \\
\hline & $\log S=0.680+0.052 \times \log A$ & 0.271 & 0.156 & - & 1.6 & 0.018 & 0.11 & 0.75 \\
\hline \multirow[t]{2}{*}{ Coleoptera (present area) } & $\log S=0.584+0.137 \times \log A+0.074 \times G$ & 0.217 & 0.161 & 0.046 & 2.4 & 0.40 & 1.31 & 0.37 \\
\hline & $\log S=0.882-0.032 \times \log A$ & 0.128 & 0.138 & - & 1.5 & 0.10 & 0.06 & 0.82 \\
\hline \multirow[t]{2}{*}{ Araneae (total area) } & $\log S=-0.979+0.780 \times \log A+0.026 \times G$ & 0.189 & 0.170 & 0.03 & 2.6 & 0.79 & 11.064 & 0.01 \\
\hline & $\log S=-0.930+0.787 \times \log A$ & 0.183 & 0.164 & - & 1.7 & 0.77 & 22.93 & $<0.01$ \\
\hline \multirow[t]{2}{*}{ Araneae $(>300 \mathrm{~m})$} & $\log S=-0.318+0.531 \times \log A+0.067 \times G$ & 0.238 & 0.153 & 0.04 & 2.6 & 0.68 & 6.33 & 0.03 \\
\hline & $\log S=-0.055+0.478 \times \log A$ & 0.235 & 0.0 .163 & - & 1.7 & 0.55 & 8.60 & 0.02 \\
\hline \multirow[t]{2}{*}{ Araneae $(>500 \mathrm{~m})$} & $\log S=-0.154+0.439 \times \log A+0.133 \times G$ & 0.405 & 0.189 & 0.068 & 2.5 & 0.53 & 2.82 & 0.15 \\
\hline & $\log S=0.523+0.204 \times \log A$ & 0.367 & 0.172 & - & 1.6 & 0.19 & 1.41 & 0.28 \\
\hline \multirow[t]{2}{*}{ Araneae (present area) } & $\log S=0.921+0.068 \times \log A-0.001 \times G$ & 0.061 & 0.046 & 0.013 & 2.4 & 0.52 & 4.34 & 0.10 \\
\hline & $\log S=0.916+0.071 \times \log A$ & 0.028 & 0.031 & - & 1.5 & 0.52 & 5.39 & 0.07 \\
\hline \multirow[t]{2}{*}{ Hemiptera (total area) } & $\log S=-0.060+0.321 \times \log A-0.007 \times G$ & 0.184 & 0.080 & 0.016 & 2.6 & 0.73 & 7.96 & 0.02 \\
\hline & $\log S=-0.070+0.319 \times \log A$ & 0.171 & 0.075 & - & 1.7 & 0.72 & 17.92 & $<0.01$ \\
\hline \multirow[t]{2}{*}{ Hemiptera $(>300 \mathrm{~m})$} & $\log S=-0.088+0.347 \times \log A+0.016 \times G$ & 0.146 & 0.067 & 0.019 & 2.6 & 0.82 & 13.27 &,$<0.01$ \\
\hline & $\log S=-0.026+0.334 \times \log A$ & 0.122 & 0.064 & - & 1.7 & 0.79 & 27.05 & 0.001 \\
\hline \multirow[t]{2}{*}{ Hemiptera $(>500 \mathrm{~m})$} & $\log S=0.334+0.145 \times \log A+0.027 \times G$ & 0.178 & 0.077 & 0.029 & 2.5 & 0.42 & 1.84 & 0.25 \\
\hline & $\log S=0.465+0.110 \times \log A$ & 0.096 & 0.056 & - & 1.6 & 0.39 & 2.88 & 0.14 \\
\hline \multirow[t]{2}{*}{ Hemiptera (present area) } & $\log S=0.491+0.088 \times \log A+0.013 \times G$ & 0.095 & 0.071 & 0.020 & 2.4 & 0.28 & 0.79 & 0.51 \\
\hline & $\log S=0.545+0.057 \times \log A$ & 0.046 & 0.050 & - & 1.5 & 0.45 & 1.28 & 0.31 \\
\hline
\end{tabular}




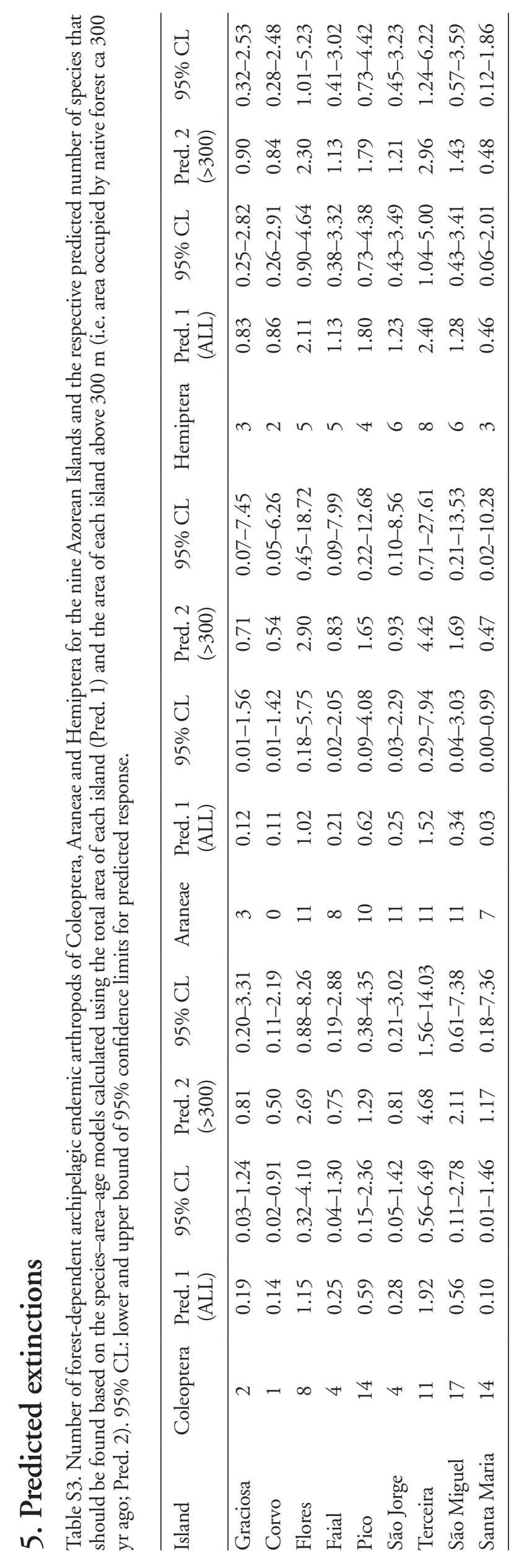




\section{Alternative mechanism}

An alternative mechanism for explaining the lack of relationship between the current extent of native forest with the number of forest dependent species, is that larger islands have more species, independent of the current area of their native forests, due to their larger size. Thus, due to the larger species pool, more species would be expected to be found in a fragment within a larger island. We tested the relationship between all the endemic species of the three taxa considered here with the total area of the islands, and compare it with the respective species-area-age relationship (Table S4). If larger islands have more forest-dependent species, then this should be valid for archipelagic endemic species in total. Note that 600 yr ago most, if not all of the islands' area was covered by native forest.

Table S4. Species-area and species-area-age models for the archipelagic endemic species of Coleoptera, Araneae and Hemiptera. Models are compared through both the adjusted $\mathrm{R}^{2}$ values and the Akaike information criterion (AIC). Both values allowed the comparison of the models that have different complexity, by penalising species-area-age models due to the higher number of parameters involved. The models with lowest AIC were preferred as they were the most informative with less complexity (more parsimonious).

\begin{tabular}{llllll}
\hline Taxon & Model & adj. $\mathrm{R}^{2}$ & F-value & p-value & AIC \\
\hline Coleoptera & Species-area & 0.57 & 11.44 & 0.01 & -24.59 \\
& Species-area-age & 0.78 & 15.24 & $<0.01$ & -30.11 \\
Araneae & Species-area & 0.71 & 20.76 & $<0.01$ & -24.53 \\
& Species-area-age & 0.68 & 9.44 & 0.01 & -22.94 \\
Hemiptera & Species-area & 0.06 & 1.49 & 0.26 & - \\
& Species-area-age & 0.02 & 1.01 & 0.42 & - \\
\hline
\end{tabular}




\section{Predictive accuracy of the species-area-age models used}

Table S5. Results of the cross-checking for the predictive accuracy of the two species-area-age models used, i.e. for the total area of the islands and for the area above $300 \mathrm{~m}$. A) Observed number of species for the total area of the islands and the respective predicted numbers using the parameter estimations from the species-area-age model of the areas $>300 \mathrm{~m}$. B) Observed number of species for the area of the islands above $300 \mathrm{~m}$ and the respective predicted numbers using the parameter estimations from the species-area-age model of total area of the islands. In all the cases the coefficient of determination $\left(\mathrm{R}^{2}\right)$ of the relationship between observed and predicted number of species (log-transformed values) was higher than $0.65(\mathrm{p}<0.05)$.

A)

Total area of islands

Coleoptera Araneae Hemiptera

\begin{tabular}{|c|c|c|c|c|c|c|}
\hline Island & Observed & Predicted & Observed & Predicted & Observed & Predicted \\
\hline Graciosa & 2 & 5.63 & 3 & 6.33 & 3 & 3.74 \\
\hline Corvo & 1 & 1.90 & 0 & 2.41 & 2 & 2.24 \\
\hline Flores & 8 & 7.63 & 11 & 9.36 & 5 & 4.94 \\
\hline Faial & 4 & 5.70 & 8 & 8.29 & 5 & 5.00 \\
\hline Pico & 14 & 7.76 & 10 & 12.57 & 4 & 6.77 \\
\hline São Jorge & 4 & 6.42 & 11 & 9.72 & 6 & 5.62 \\
\hline Terceira & 11 & 17.80 & 11 & 19.94 & 8 & 7.41 \\
\hline São Miguel & 17 & 27.27 & 11 & 30.04 & 6 & 9.39 \\
\hline Santa Maria & 14 & 31.08 & 7 & 19.18 & 3 & 5.37 \\
\hline
\end{tabular}

B)

\begin{tabular}{|c|c|c|c|c|c|c|}
\hline \multirow[b]{3}{*}{ Island } & \multicolumn{4}{|c|}{ Area of islands above $300 \mathrm{~m}$} & \multirow{2}{*}{\multicolumn{2}{|c|}{ Hemiptera }} \\
\hline & \multicolumn{2}{|c|}{ Coleoptera } & \multicolumn{2}{|c|}{ Araneae } & & \\
\hline & Observed & Predicted & Observed & Predicted & Observed & Predicted \\
\hline Graciosa & 2 & 0.44 & 2 & 0.32 & 1 & 1.25 \\
\hline Corvo & 1 & 0.63 & 0 & 0.63 & 2 & 1.77 \\
\hline Flores & 7 & 3.89 & 11 & 4.18 & 5 & 3.65 \\
\hline Faial & 3 & 2.70 & 8 & 3.37 & 5 & 3.53 \\
\hline Pico & 13 & 5.52 & 10 & 8.21 & 4 & 5.19 \\
\hline São Jorge & 4 & 4.36 & 11 & 5.99 & 6 & 4.50 \\
\hline Terceira & 10 & 7.54 & 11 & 7.37 & 7 & 4.37 \\
\hline São Miguel & 17 & 13.06 & 10 & 12.96 & 5 & 5.41 \\
\hline Santa Maria & 13 & 2.90 & 7 & 1.27 & 3 & 1.77 \\
\hline
\end{tabular}

Considering the uncertainty inherent in analysing a system for which we have excellent present day distributional data but lack systematic historical distribution data, two conclusions may be drawn. First, the result from the $>300 \mathrm{~m}$ area calculation suggests that there may have been more species originally present than are now known, indicating that some extinction may already have occurred in the period since forest loss was first initiated by people (see Cardoso et al. 2010). Second, the results for the total area, which underestimates the species number found only above 300 $\mathrm{m}$, supports the contention that there is an extinction-debt still to pay for the species found above $300 \mathrm{~m}$. 


\section{Test for autocorrelation of the residuals of the species-area-age models used.}

Table S6. Results for the Durbin-Watson statistic to detect the presence of autocorrelation in the residuals from the species-areaage models applied (Table 3 ) (lower critical value $=0.629$; upper critical value $=1.699)$. This statistic tests for autocorrelation in the residuals from a regression analysis. If the value is below the lower critical value there is positive autocorrelation; if the value is above the upper critical value there is no autocorrelation; if the value is between both critical values the test is inconclusive.

\begin{tabular}{lc}
\hline Data set & Durbin-Watson values \\
\hline Coleoptera total area & 2.030 \\
Coleoptera $(300 \mathrm{~m})$ & 3.030 \\
Araneae total area & 2.010 \\
Araneae $(300 \mathrm{~m})$ & 1.436 \\
Hemiptera total area & 2.755 \\
Hemiptera $(300 \mathrm{~m})$ & 3.377 \\
\hline
\end{tabular}




\section{Comparing species abundances}

In order to evaluate our predictions based on the available data on species abundance, we compare the average species abundance per transect (i.e. average number of individuals of archipelagic endemic forest-dependent species per transect) for Graciosa Island, with the rest of the archipelagos islands (Table S7). Currently there is no primary native forest on Graciosa; only a very small patch of secondary native vegetation occurs, dominated by small-sized Erica azorica, an early successional endemic shrub. Hence our prediction is that for the surviving forest-dependent species their abundance should be indicative of a progressive reduction towards extinction.

Based on the total area of the remaining forest fragments in each island, the rest of the islands were divided in two categories: Islands with large fragments, with total native forest area $>9 \mathrm{~km}^{2}$ (i.e. Terceira, Pico and Flores) and islands with small fragments, with total native forest area $<3 \mathrm{~km}^{2}$ (i.e. Santa Maria, Faial, São Miguel and São Jorge) (Table S7).
The pattern arising from the comparison of the rest of the islands, is quite fuzzy, concurring with a number of studies concluding that the responses to forest loss and fragmentation related to the abundance can be strikingly species-specific and at times highly idiosyncratic (Fahrig 2001, Tscharntke et al. 2002). At the same time, the phenomenon of density compensation as a result of the extinction of competitors and/or predators cannot be excluded (Whittaker and Fernández-Palacios 2007); see for example the average abundance of Gibbaranea occidentalis in Santa Maria, the island with the smallest fragment of native forest.

Table S7. Average abundance per transect (i.e. average number of species individuals per transect) of archipelagic endemic forestdependent species of Coleoptera, Araneae, and Hemiptera present in Graciosa Island, in comparison with the rest of the archipelagic islands. The islands were grouped by the size of remaining native forest fragments. TER - Terceira; PIC - Pico; FLO - Flores; São Jorge; SMG - São Miguel; FAI - Faial; SMR - Santa Maria; GRA - Graciosa.

\begin{tabular}{|c|c|c|c|c|c|c|c|c|c|}
\hline \multirow[b]{2}{*}{ Species } & \multirow[b]{2}{*}{ Family } & \multicolumn{4}{|c|}{ Large forest remnants } & \multicolumn{4}{|c|}{ Small forest remnants } \\
\hline & & GRA & TER & PIC & FLO & SMG & SJG & FAI & SMR \\
\hline \multicolumn{10}{|l|}{ Coleoptera } \\
\hline Laparocerus azoricus & Curculionidae & 0.09 & 2.53 & & & 0.25 & 0.25 & & \\
\hline Metophthalmus occidentalis & Lathridiidae & 0.09 & & & & & & & 1 \\
\hline \multicolumn{10}{|l|}{ Araneae } \\
\hline Gibbaranea occidentalis & Araneidae & 0.09 & 29.78 & 14.44 & 10.58 & 21.00 & 15.25 & 5.13 & 46.25 \\
\hline Pisaura acoreensis & Pisauridae & 0.09 & 1.00 & 1.38 & 1.25 & 0.92 & 2.25 & & \\
\hline Rugathodes acoreensis & Theridiidae & 0.09 & 39.35 & 22.75 & 7.67 & 38.67 & 48.00 & 3.25 & 15.00 \\
\hline \multicolumn{10}{|l|}{ Hemiptera } \\
\hline Aphrodes hamiltoni & Cicadellidae & 0.91 & 5.25 & 7.38 & 8.33 & 0.50 & 8.25 & 5.75 & 7.50 \\
\hline Eupteryx azorica & Cicadellidae & 0.09 & 0.14 & 0.063 & & 0.063 & 0.75 & & \\
\hline Pinalitus oromii & Miridae & 0.09 & 14.58 & 48.94 & 17.92 & 6.25 & 50.25 & 22.63 & 33.00 \\
\hline
\end{tabular}




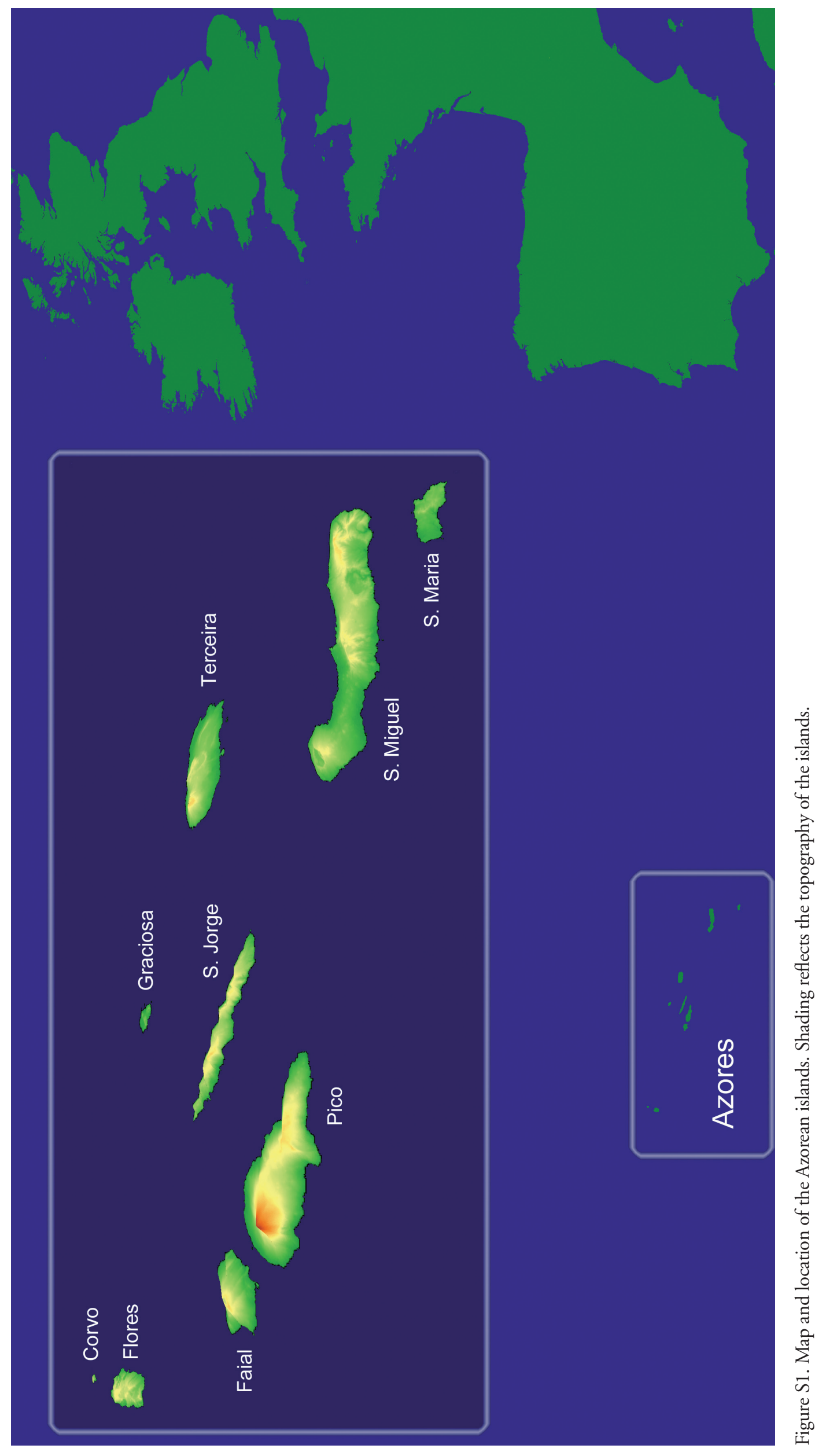




\section{References}

Basset, Y. 1999. Diversity and abundance of insect herbivores collected on Castanopsis acuminatissima (Fagaceae) in New Guinea: relationships with leaf production and surrounding vegetation. - Eur. J. Entomol. 96: 381-391.

Borges, P. A. V. and Brown, V. K. 1999. Effect of island geological age on the arthropod species richness of Azorean pastures. - Biol. J. Linn. Soc. 66: $373-410$.

Borges, P. A. V. and Wunderlich, J. 2008. Spider biodiversity patterns and their conservation in the Azorean archipelago, with descriptions of new species. - Syst. Biodivers. 6: 249-282.

Borges, P. A. V. and Hortal, J. 2009. Time, area and isolation: factors driving the diversification of Azorean arthropods. - J. Biogeogr. 36: 178-191.

Borges, P. A. V. et al. 2005. Ranking protected areas in the Azores using standardised sampling of soil epigean arthropods. - Biodivers. Conserv. 14: 2029-2060.

Borges, P. A. V. et al. 2006a. Arthropod biodiversity - Graciosa Island. - ARENA.

Borges, P. A. V. et al. 2006b. Invasibility and species richness of island endemic arthropods: a general model of endemic vs. exotic species. J. Biogeogr. 33: 169-187.

Cardoso, P. et al. 2008a. Assessing spider species richness and composition in Mediterranean cork oak forests. - Acta Oecol. 33: 114-127.

Cardoso, P. et al. 2008b. Rapid biodiversity assessment of spiders (Araneae) using semi-quantitative sampling: a case study in a Mediterranean forest. - Insect Conserv. Divers. 1: 71-84.

Cardoso, P. et al. 2009. A spatial scale assessment of habitat effects on arthropod communities of an oceanic island. - Acta Oecol. 35: 590-597.
Cardoso, P. et al. 2010. Drivers of diversity in Macaronesian spiders and the role of species extinctions. - J. Biogeogr. 37, doi: 10.1111/j.13652699.2009.02264.x.

Chao, A. 1984. Non-parametric estimation of the number of classes in a population. - Scand. J. Stat. 11: 265-270.

Fahrig, L. 2001. How much habitat is enough? - Biol. Conserv. 100: $65-74$.

Gaspar, C. et al. 2008. Diversity and distribution of arthropods in native forests of the Azores archipelago. - Arquipélago-Life Mar. Sci. 25: $1-30$.

Gotelli, N. J. and Colwell, R. K. 2001. Quantifying biodiversity: procedures and pitfalls in the measurement and comparison of species richness. - Ecol. Lett. 4: 379-391.

Lopes, D. et al. 2005. The fruit production in Macaronesia - The contribution of Project INTERFRUTA for its improvement. - Univ. Azores.

Tscharntke, T. et al. 2002. Characteristics of insect populations on habitat fragments: a mini review. - Ecol. Res. 17: 229-239.

Turquin, M.-J. 1973. Une biocenose cavernicole originale pour le Bugey: Le puits de Rappe. - In: Commptes Rendus 96e Congresse Naturel Sociétès Savantes, Toulouse 1971. Sciences, 3, pp. 235-256.

Whittaker, R.J. et al. 2008. A general dynamic theory of oceanic island biogeography. - J. Biogeogr. 35: 977-994.

Whittaker, R. J. and Fernández-Palacios, J. M. 2007. Island biogeography: ecology, evolution, and conservation, 2nd ed. - Oxford Univ. Press. 